\title{
Viscoelastically prestressed polymeric matrix composites - Effects of test span and fibre volume fraction on Charpy impact characteristics
}

\author{
Adnan Fazal, Kevin S. Fancey* \\ Department of Engineering, University of Hull, Hull HU6 7RX, UK
}

\section{A R T I C L E I N F O}

\section{Article history:}

Received 6 January 2012

Received in revised form 2 March 2012

Accepted 5 April 2012

Available online 12 April 2012

\section{Keywords:}

A. Polymer-matrix composites

B. Impact behaviour

D. Mechanical testing

Prestress

\begin{abstract}
A B S T R A C T
A viscoelastically prestressed polymeric matrix composite (VPPMC) is produced by subjecting polymeric fibres to tensile creep, the applied load being removed before moulding the fibres into a resin matrix. After matrix curing, the viscoelastically strained fibres impart compressive stresses to the surrounding matrix, thereby improving mechanical properties. This study investigated the mechanisms considered responsible for VPPMCs improving impact toughness by performing Charpy impact tests on unidirectional nylon 6,6 fibre-polyester resin samples over a range of span settings (24-60 $\mathrm{mm}$ ) and fibre volume fractions (3.3-16.6\%). Comparing VPPMC samples with control (unstressed) counterparts, the main findings were: (i) improved impact energy absorption (up to 40\%) depends principally on shear stressinduced fibre-matrix debonding (delamination) and (ii) energy absorption improves slightly with increasing fibre volume fraction, but the relationship is statistically weak. The findings are discussed in relation to improving the impact performance of practical structures.
\end{abstract}

(c) 2012 Elsevier Ltd. All rights reserved.

\section{Introduction}

A viscoelastically prestressed polymeric matrix composite (VPPMC) is produced by applying tension to polymeric fibres, thereby causing viscoelastic creep. The tensile load is then released before moulding the fibres into a matrix and, following matrix solidification, compressive stresses are imparted by the strained fibres as they attempt viscoelastic recovery. This matrix compression, which is balanced by residual tension within the fibres, can improve mechanical properties. A similar state of matrix compression-fibre tension may also be achieved with an elastically prestressed PMC (EPPMC): here, fibres are subjected to elastic strain during matrix curing to achieve the required prestress. Results from studies of unidirectional glass fibre EPPMCs indicate that elastic prestressing could increase tensile strength by $\sim 25 \%$, elastic modulus by $\sim 50 \%$ [1] and impact resistance, flexural stiffness and strength by up to $33 \%[2,3]$, when compared with unstressed (control) counterparts. Explanations for such improvements have been based on matrix compression and fibre tension effects which can impede or deflect propagating cracks and reduce composite strain resulting from external tensile or bending loads [1-3]. The improvements offered by VPPMCs may also be similarly considered. Moreover, VPPMCs offer two potentially important benefits over EPPMCs. First, the VPPMC fibre stretching and moulding

\footnotetext{
* Corresponding author. Tel.: +44 1482 465071; fax: +44 1482466664 .

E-mail address: k.s.fancey@hull.ac.uk (K.S. Fancey).
}

operations are de-coupled, so the stretching process imposes no constraints on fibre orientation, length and spatial distribution, which could restrict the moulding of complex product geometries. Second, in an EPPMC, localised matrix creep near the fibre-matrix interface would be expected to cause a gradual deterioration in prestress; in a VPPMC however, this effect would be offset by an active response from longer term recovery mechanisms within the polymeric fibres [4].

Research into VPPMCs has advanced from a feasibility study [5] to a stage where the basic mechanical (tensile and flexural) properties have been evaluated [6,7]. Tensile tests [6] demonstrated increases in strength, modulus and energy absorbed (to 0.25 strain) to exceed $15 \%, 30 \%$ and $40 \%$ respectively and the flexural modulus from three-point bend tests [7] was found to be $\sim 50 \%$ greater than corresponding control samples. There was however an intermediate period of several years in which effects relating to long-term behaviour required investigation [4,8-11]. The longterm mechanical performance of VPPMCs was characterised through Charpy impact testing [4,8,11], culminating in the most recent study, which (i) demonstrates no deterioration in impact performance over a duration equivalent to $40^{\circ} \mathrm{C}$ ambient for $\sim 20$ years and (ii) shows that VPPMC samples absorb, on average, $\sim 30 \%$ more impact energy than their control (unstressed) counterparts [12]. To date, all composite specimens for evaluation by Charpy impact testing have been produced at a very low fibre volume fraction $\left(V_{\mathrm{f}}\right)$. To investigate fracture and energy absorption characteristics further, this paper reports on Charpy impact evaluation over a range of test span settings and $V_{\mathrm{f}}$ values. 


\section{Background}

\subsection{The ISO 179 standard and published Charpy impact investigations}

The Charpy test is a well-known simple method for evaluating impact toughness. For plastics, the EN ISO 179 standard [13] describes three test specimen types, detailing their dimensions and required span, $L$. Unnotched Type 2 or Type 3 specimens are used for materials capable of exhibiting interlaminar shear (e.g. long fibre-reinforced materials), these being tested 'flatwise' or 'edgewise' to the pendulum blow direction. Thus flatwise orientation is most appropriate for evaluation of prestress effects. Preferred specimen thickness, $h$, is $3 \mathrm{~mm}$ for Types 2 and 3 and the standard states there are no other specified specimen sizes, the most important parameter being the $L / h$ ratio for flatwise testing. For Type $2, L$ is $20 h$ but this is lower for Type 3 , being $6 h$ or $8 h$. The choice between Type 2 and Type 3 is determined by the nature of failure: according to the standard, these are expected to be tensile-type failures for Type 2 and interlaminar shear failures for Type 3 specimens.

Table 1 provides an overview, using information from published papers, of typical conditions used for Charpy (flatwise) impact tests on fibre-reinforced polymeric composite specimens. In most cases, where information is available, a range of failure mechanisms is reported, from fibre debonding or delamination (interlaminar shear) through to tensile, i.e. cleavage-type transverse fractures from brittle specimens. Common $L$ settings are 40 and $60 \mathrm{~mm}$ and, with varying specimen thicknesses, the range of $L / h$ values is extensive.

It is well known that the contribution to beam deflection from shearing forces becomes increasingly significant as $L / h$ is decreased [7]. Adams and Miller [14] highlighted the effects of shear stress during beam failure and, although principally a study based on static flexural testing, they also reported findings from Charpy tests on thick $(10 \mathrm{~mm})$ and thinner $(\sim 2.5 \mathrm{~mm})$ polymeric composite specimens (Table 1 ). For the $10 \mathrm{~mm}$ thick specimens, contributions from shear effects were increased by the small $L / h$ value (i.e. 4 ) and, although the thinner specimens raised $L / h$ to 16 , it may be inferred from Ref. [14] that this caused no substantial change.

In the context of $L / h$ values, the work of Nagai and Miyairi [15] in Table 1 is of particular interest. From Charpy tests, if impact energy is considered to be absorbed within the specimen volume defined by span size, the impact energy per unit volume, $u$, can be defined as:

$u=\frac{U}{b h L}$

where $U$ is the measured impact energy and $b$ is the specimen width. It was found in Ref. [15] that the contribution from shear-induced delamination failure decreased with increasing $L / h$, causing $u$ to reach an approximately constant (minimum) value for $L / h \geqslant 20$ for unidirectional CFRP specimens and $L / h \geqslant 16$ for woven CFRP specimens. Thus provided that $L / h$ is sufficiently large, $u$ effectively becomes independent of $L$ and specimen dimensions, making it a potentially useful parameter for comparative purposes. By using such large $L / h$ values however, these findings presuppose that Charpy test conditions should be set up to promote energy absorption through elastic deflection, followed by failure through transverse fracture, in preference to failure by delamination. Nevertheless, compared with bending strength, CFRPs have inferior interlaminar shear strength [15] and when subjected to general impact conditions, delamination becomes a major failure mechanism [18,24].

\subsection{Published Charpy impact test work on prestressed composites}

In contrast with views supporting the use of large $L / h$ values, our evaluation of VPPMCs by Charpy testing has, to date, focused on using an $L / h$ value of $\sim 8$. With sample dimensions $(80 \times 10 \times$ $3.2 \mathrm{~mm}$ ) concurring closely with ISO 179 Specimen Type 2 , the appropriate span would have been $60 \mathrm{~mm}$; however, $L$ was set to $24 \mathrm{~mm}$, in accordance with Specimen Type 3. Originally, the available nylon yarn for moulding VPPMC samples limited $V_{\mathrm{f}}$ to $2-3 \%$, hence the shorter span prevented the possibility of some samples falling below the minimum energy readings set by the standard $[4,5,8,11]$. To be consistent with these earlier studies, the most recent work [12] also adopted the same $V_{\mathrm{f}}$ and test parameters.

The Charpy impact testing of EPPMCs by Motahhari and Cameron [2] also used a similar $L / h$ value $(\sim 8.5$, Table 1$)$ to our work. They found that the impact energy absorption of glass fibre-epoxy specimens could be increased by up to $33 \%$ from elastically generated prestress, i.e. comparable to that achieved by viscoelastic prestressing ( 30\%) [12]. In Ref. [2], the principal mechanism cited for this improvement was impact-induced fibre-matrix interfacial debonding in preference to transverse fracture of fibres. This debonding mechanism absorbs more impact energy than transverse fracture and is promoted by the residual shear stresses at fibre-matrix interfaces caused by elastic [2] or viscoelastic [12] fibre prestressing.

In this study, it is suggested that prestress-induced interfacial shear stresses (which promote debonding) are activated by externally imposed stresses from shearing forces caused by the impact event. Thus shear stress-induced debonding from impact is enhanced by the presence of prestress. Since the contribution from impact-induced shear effects should decrease with increasing $L / h$, we propose that the benefits provided by prestress-induced interfacial shear stresses may diminish at larger span settings

\section{Table 1}

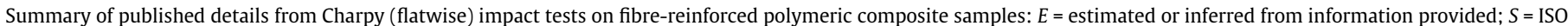
179 specified with no further information; $\mathrm{D}=$ failure by fibre debonding or delamination; $\mathrm{T}$ = tensile (brittle, cleavage) failure.

\begin{tabular}{|c|c|c|c|c|c|c|c|c|}
\hline Ref. & Year & Principal fibre & Matrix & Specimen size $(\mathrm{mm})$ & Span $(\mathrm{mm})$ & $L / h$ & ISO 179 specimen type & Principal failure mode \\
\hline \multirow[t]{2}{*}{ [14] } & 1976 & Carbon & Epoxy & $55 \times 10 \times 10$ & 40 & 4 & - & $\mathrm{D} E$ \\
\hline & & & & $55 \times 10 \times 2.5 E$ & 40 & $16 E$ & - & - \\
\hline \multirow[t]{2}{*}{ [15] } & 1994 & Carbon & Epoxy & $(L+20) \times 10 \times(1-5)$ & $30-100$ & $6-40$ & - & $\mathrm{D}, \mathrm{T}$ \\
\hline & & & & $(L+30) \times 10 \times 1$ & 60,90 & 60,90 & - & $\mathrm{T}$ \\
\hline$[2]$ & 1998 & Glass & Epoxy & $81 \times 19 \times 6$ & $50 E$ & $8.5 E$ & - & $\mathrm{D}$ \\
\hline [16] & 1998 & Glass & Epoxy & $? \times 5 \times 2$ & 40 & 20 & - & - \\
\hline \multirow[t]{2}{*}{ [17] } & 2008 & Carbon & Epoxy & $80 \times 10 \times 3$ & 60 & 20 & 2 & $\mathrm{D}, \mathrm{T}$ \\
\hline & & & & $80 \times 10 \times 5$ & 60 & 12 & - & $\mathrm{D}, \mathrm{T}$ \\
\hline [18] & 2008 & Carbon & Epoxy & $80 \times 10 \times 1.7$ & 40 & 23.5 & - & $\mathrm{D}, \mathrm{T}$ \\
\hline [19] & 2009 & Jute/cellulose & PP & - & - & - & $S$ & - \\
\hline [20] & 2010 & Glass/carbon & Epoxy & $80 \times 15 \times 1.5$ & $60 E$ & $40 E$ & - & $\mathrm{D}, \mathrm{T}$ \\
\hline [21] & 2010 & Glass & Epoxy & $80 \times 15 \times 4$ & $62 E$ & $15.5 E$ & 1 & $\mathrm{D}, \mathrm{T}$ \\
\hline [22] & 2010 & Glass & HDPE/wood & - & - & - & $S$ & - \\
\hline [23] & 2010 & Glass & Nylon & $80 \times 10 \times 4$ & $62 E$ & $15.5 E$ & 1 & - \\
\hline
\end{tabular}


(for a constant $h$ ). A further hypothesis is that specimens with higher $V_{\mathrm{f}}$ values will increase opportunities for energy absorption through prestress-enhanced fibre debonding.

It should be noted that studies on unidirectional fibre PMCs commonly refer to failure by delamination rather than (generic) fibre debonding, reflecting the use of prepregs $[14,15,17,20]$ as opposed to separate fibres in unidirectional EPPMCs [2] and VPPMCs [12]. For the current study, we suggest that sample (flatwise) testing geometry and resulting (shear-induced) failure effectively render both terms interchangeable for macroscopic observations.

\section{Experimental}

General details of sample production and impact test procedures have been published previously $[4,5,8,11,12]$ and are summarised here. Fibre reinforcement was from continuous multi-filament nylon 6,6 yarn (140 filaments, $27.5 \mu \mathrm{m}$ filament diameter), supplied by Goodfellow Cambridge Ltd. Batches of composite samples were produced at three $V_{\mathrm{f}}$ values, i.e. $3.3 \%, 10.0 \%$ and $16.6 \%$. For each batch, sufficient yarn was annealed in a fan-assisted oven $\left(150^{\circ} \mathrm{C}\right.$, $0.5 \mathrm{~h}$ ). Following this, yarn designated for (prestressed) test samples was attached to a bespoke stretching rig and subjected to $340 \mathrm{MPa}$ tensile creep stress for $24 \mathrm{~h}$, whilst equivalent (annealed) control yarn was positioned in close proximity to the stretching rig for exposure to the same ambient conditions $\left(19.5-21{ }^{\circ} \mathrm{C}, 30-50 \%\right.$ $\mathrm{RH})$. Both yarns were then folded, cut into multiple lengths and combed into flat ribbons ready for moulding.

Immediately prior to moulding, control yarns were observed to exhibit slightly more waviness than corresponding test yarns. Since $V_{\mathrm{f}}$ calculations were based on fibre and composite sample cross-sectional areas, $V_{\mathrm{f}}$ would have tended to be higher in the resulting composite control samples. Nevertheless, the effect on $V_{\mathrm{f}}$ will have been minimal: from linear measurements of these yarns, we estimate $V_{\mathrm{f}}$ to be less than 1.015 times that of composite test sample counterparts.

The matrix resin was Cray Valley Norsodyne E9252, mixed with 1\% MEKP catalyst, supplied by CFS Fibreglass Supplies, UK. This was a clear-casting polyester resin, selected here for its high filler loading capability. Gel time was $\sim 15 \mathrm{~min}$ and the resin was considered sufficiently cured after $2 \mathrm{~h}$ (at room temperature) to allow demoulding. Unidirectional continuous fibre composite samples were prepared by open-casting. Two aluminium moulds were used, each with a $10 \mathrm{~mm}$ wide channel enabling a strip of test and control materials to be cast simultaneously from the same resin mix; this procedure was completed within $0.5 \mathrm{~h}$ of the fibre stretching process. Following demoulding, the test and control strips were each cut into five samples, the sample size being $80 \times 10 \times 3.2 \mathrm{~mm}$. These samples were then held under a weighted steel strip for $24 \mathrm{~h}$ to prevent potential bending effects from internal stresses. The resulting batch (of five test and five control samples) was subsequently sealed in polythene bags and stored at room temperature $\left(18-22^{\circ} \mathrm{C}\right)$ prior to impact testing at $336 \mathrm{~h}$ ( 2 weeks) after moulding.

A Ceast Resil 25 Charpy machine with (non-instrumented) 7.5 or $15 \mathrm{~J}$ hammer was used for impact testing at $3.8 \mathrm{~m} \mathrm{~s}^{-1}$, which operated in accordance with Ref. [13]. As observed with previous Charpy-based studies using open-cast polyester matrix samples $[4,5,8,11,12]$, fibres tended to settle towards the bottom of the mould prior to curing, an effect most easily observed at the lowest $V_{\mathrm{f}}(3.3 \%)$. Thus for all our impact tests, samples were mounted with the fibre-rich side facing away from the pendulum hammer and a diagram of this configuration has been previously published [5,8]. For each $V_{\mathrm{f}}$, three batches were impact tested at span settings of 24 , 40 and $60 \mathrm{~mm}$. Despite meticulous set-up procedures and alignment checks, some samples at 40 and $60 \mathrm{~mm}$ spans were observed to be susceptible to being struck off-centre by the Charpy hammer, the effect being most significant at $60 \mathrm{~mm}$ span.

\section{Results}

\subsection{Initial observations}

Fig. 1 shows cross sections, representing typical fibre spatial distributions of all samples studied. For both test and control samples, fibre concentration was greatest towards the bottom of the moulding, the effect being most prominent at $3.3 \% V_{\mathrm{f}}$, where the fibre-rich region occupies only $\sim 35-40 \%$ of the cross-sectional area. As reported in Section 3, this concurs with previous Charpy-based studies using open-cast polyester matrix samples, hence $V_{\mathrm{f}}$ calculations represent average values.

Of particular concern however, was whether there were any systematic differences in spatial distribution between equivalent test and control samples. Fig. 1 shows some tendency towards the concentration gradient of fibres in control samples being more diffuse than the corresponding test samples. Although this may be attributed to control yarn waviness (Section 3), it was not observed in cross sections from a previous study [7], where a different polyester resin was used. Thus minor differences in resin curing characteristics may have exacerbated this effect. A more diffusely distributed layer of fibres might be expected to increase the total fibre-matrix interface area available for energy absorption (through debonding), thereby preferentially improving the Charpy impact

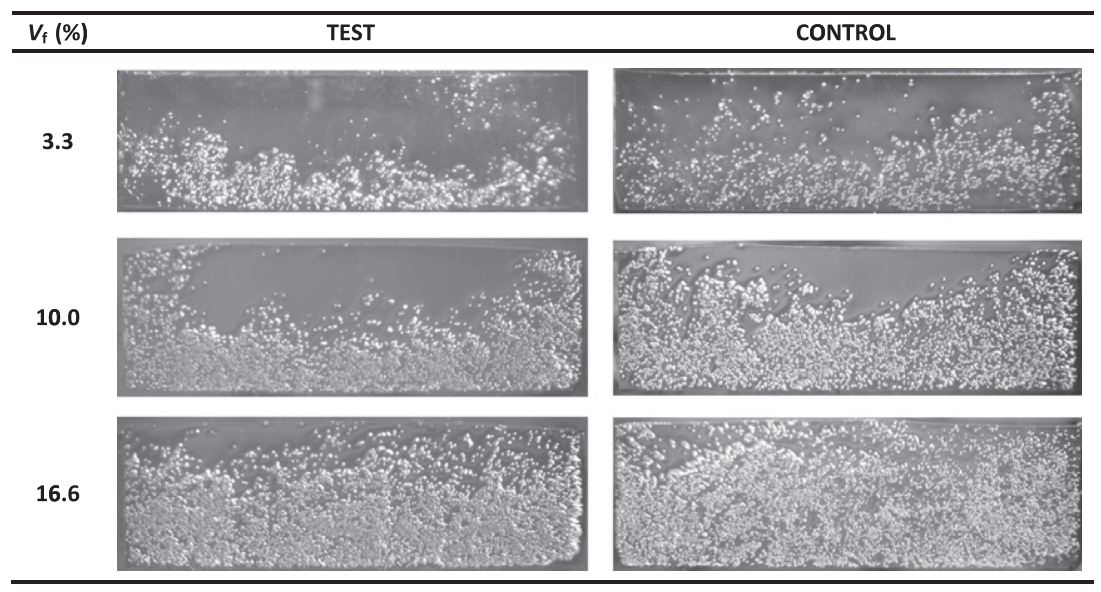

Fig. 1. Representative optical micrograph (polished) sections of all samples evaluated. 


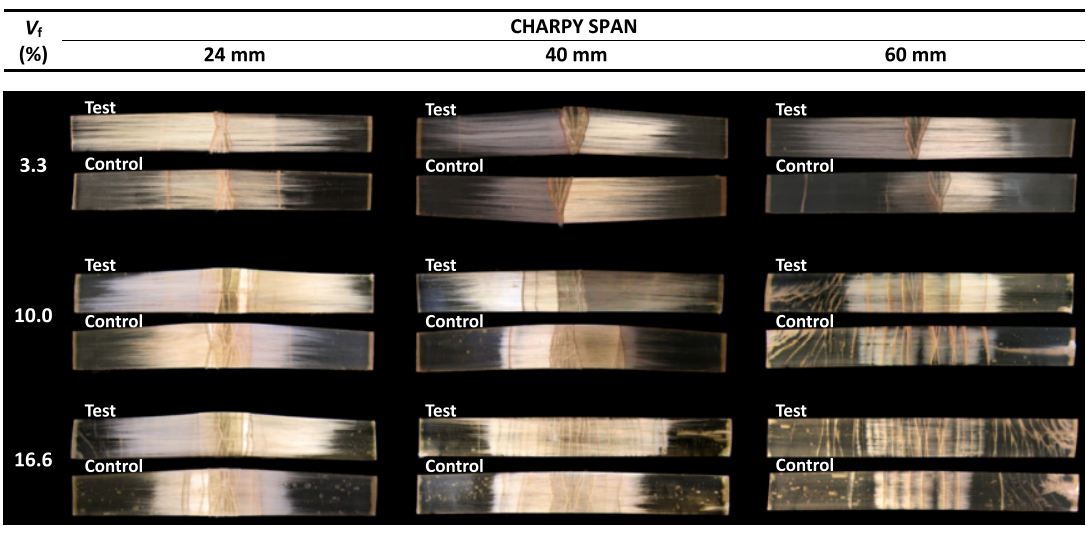

Fig. 2. Representative fracture and delamination characteristics observed from (prestressed) test and (unstressed) control samples for each $V_{\mathrm{f}}$ value and span setting.

toughness of the control samples. Although undesirable, we suggest that this, combined with the marginally higher $V_{\mathrm{f}}($ Section 3$)$ in the control samples would have had negligible effects on the results.

Fig. 2 shows representative fractures from (prestressed) test and (unstressed) control samples at the three span settings. For all $V_{\mathrm{f}}$ values at $24 \mathrm{~mm}$ span and all span settings at 3.3\% $V_{\mathrm{f}}$, samples generally exhibited a small cluster of fractures in the central region, sometimes with a vertical crack at either side in the vicinity of the Charpy anvil shoulders. This was consistent with samples being pushed through the anvil shoulders following impact and remaining in a deformed state with a ' $V$ ' shaped profile after testing. For $10 \%$ and $16.6 \% V_{\mathrm{f}}$, a wider spread of multiple (predominantly) vertical cracks was observed, particularly at larger spans, concurring with a transition to fractured samples with more curved deformation profiles. Larger spans also left samples with less residual deformation after testing.

As reported in Section 3, samples tested at $60 \mathrm{~mm}$ span were most susceptible to being struck off-centre by the Charpy hammer. Owing to the more centralised fracture pattern, this was more easily observed at $3.3 \% V_{\mathrm{f}}$. We estimate that $\sim 60 \%$ of all $3.3 \% V_{\mathrm{f}}$ samples tested at $60 \mathrm{~mm}$ span were fractured 3-8 $\mathrm{mm}$ off-centre. At $10 \%$ and $16.6 \% V_{\mathrm{f}}$, more than half of the $60 \mathrm{~mm}$ span samples also showed multiple diagonal cracking at one end, as seen in Fig. 2. Unlike through-thickness damage in the main fracture region, these cracks were restricted to the matrix-rich side (facing the hammer). We suggest that the off-centre impacts and diagonal cracking are symptoms of (unwanted) lateral sample movement during testing; this can be attributed to the limited sample support at the $60 \mathrm{~mm}$ span setting, as discussed in Section 5.1 .

In previous studies $(L=24 \mathrm{~mm})$, the region of impact-induced delamination in test samples was found to be greater than that of their control counterparts $[5,8,11,12]$ and this can also be observed at all span settings in Fig. 2. Moreover, for higher $V_{\mathrm{f}}$ test and control samples, Fig. 2 shows the multiple vertical cracks at larger spans tending to produce delamination regions of a more discontinuous nature.

\subsection{Effects of span and fibre volume fraction on prestress-induced energy increase}

Table 2 summarises the impact test data. From this, Fig. 3 shows the increase in impact energy absorbed (test samples relative to control counterparts) as a function of $V_{\mathrm{f}}$ for each span setting. The considerable batch-to-batch variation seen in Table 2 is denoted by the error bars. Since these represent uncertainty in the mean values (standard errors), identification of any trends in Fig. 3 requires caution.
Table 2

Impact test results from composite sample batches: 5 (prestressed) test and 5 (unstressed) control samples per batch. SE is the standard error of the mean.

\begin{tabular}{|c|c|c|c|c|c|}
\hline \multirow[t]{2}{*}{$\begin{array}{l}V_{\mathrm{f}} \\
(\%)\end{array}$} & \multirow[t]{2}{*}{$\begin{array}{l}\text { Span } \\
(\mathrm{mm})\end{array}$} & \multicolumn{2}{|c|}{$\begin{array}{l}\text { Mean impact energy } \\
\left(\mathrm{kJ} \mathrm{m}^{-2}\right)\end{array}$} & \multirow[t]{2}{*}{$\begin{array}{l}\text { Increase in } \\
\text { energy (\%) }\end{array}$} & \multirow[t]{2}{*}{$\begin{array}{l}\text { Mean increase in } \\
\text { energy }(\% \pm \mathrm{SE})\end{array}$} \\
\hline & & Test $\pm \mathrm{SE}$ & Control \pm SE & & \\
\hline 3.3 & 24 & $\begin{array}{l}91.2 \pm 1.0 \\
92.0 \pm 2.0 \\
88.7 \pm 4.0\end{array}$ & $\begin{array}{l}61.8 \pm 3.2 \\
69.6 \pm 1.5 \\
64.7 \pm 1.5\end{array}$ & $\begin{array}{l}47.5 \\
32.1 \\
37.1\end{array}$ & $38.9 \pm 4.5$ \\
\hline 3.3 & 40 & $\begin{array}{l}71.1 \pm 2.5 \\
73.4 \pm 3.1 \\
67.6 \pm 2.1\end{array}$ & $\begin{array}{l}64.9 \pm 2.1 \\
63.7 \pm 2.2 \\
66.7 \pm 4.4\end{array}$ & $\begin{array}{r}9.5 \\
15.2 \\
1.3\end{array}$ & $8.7 \pm 4.1$ \\
\hline 3.3 & 60 & $\begin{array}{l}33.9 \pm 2.5 \\
41.9 \pm 3.7 \\
38.9 \pm 1.9\end{array}$ & $\begin{array}{l}35.4 \pm 3.2 \\
40.1 \pm 0.8 \\
40.1 \pm 1.7\end{array}$ & $\begin{array}{r}-4.1 \\
4.3 \\
-3.1\end{array}$ & $-1.0 \pm 2.7$ \\
\hline 10.0 & 24 & $\begin{array}{l}250.8 \pm 6.1 \\
204.9 \pm 12.9 \\
205.8 \pm 13.7\end{array}$ & $\begin{array}{l}165.6 \pm 9.6 \\
156.4 \pm 7.0 \\
171.8 \pm 13.9\end{array}$ & $\begin{array}{l}51.4 \\
31.0 \\
19.8\end{array}$ & $34.0 \pm 9.3$ \\
\hline 10.0 & 40 & $\begin{array}{l}160.2 \pm 1.8 \\
179.8 \pm 2.4 \\
143.6 \pm 2.7\end{array}$ & $\begin{array}{l}149.1 \pm 3.3 \\
152.7 \pm 4.0 \\
128.5 \pm 1.3\end{array}$ & $\begin{array}{r}7.5 \\
17.7 \\
11.7\end{array}$ & $12.3 \pm 3.0$ \\
\hline 10.0 & 60 & $\begin{array}{l}87.5 \pm 2.7 \\
85.6 \pm 2.9 \\
85.7 \pm 3.9\end{array}$ & $\begin{array}{l}78.1 \pm 4.9 \\
76.6 \pm 5.0 \\
73.6 \pm 2.6\end{array}$ & $\begin{array}{l}12.1 \\
11.7 \\
16.4\end{array}$ & $13.4 \pm 1.5$ \\
\hline 16.6 & 24 & $\begin{array}{l}265.8 \pm 8.9 \\
300.7 \pm 8.3 \\
282.7 \pm 2.4\end{array}$ & $\begin{array}{l}214.2 \pm 9.4 \\
234.4 \pm 9.9 \\
227.4 \pm 9.1\end{array}$ & $\begin{array}{l}24.1 \\
28.3 \\
24.3\end{array}$ & $25.6 \pm 1.4$ \\
\hline 16.6 & 40 & $\begin{array}{l}202.5 \pm 2.2 \\
212.5 \pm 4.6 \\
217.5 \pm 4.3\end{array}$ & $\begin{array}{l}175.3 \pm 5.5 \\
181.0 \pm 5.7 \\
192.5 \pm 5.1\end{array}$ & $\begin{array}{l}15.5 \\
17.4 \\
13.0\end{array}$ & $15.3 \pm 1.3$ \\
\hline 16.6 & 60 & $\begin{array}{r}103.9 \pm 2.6 \\
99.4 \pm 1.8 \\
111.5 \pm 1.5\end{array}$ & $\begin{array}{r}103.8 \pm 4.5 \\
87.8 \pm 5.4 \\
97.4 \pm 1.7\end{array}$ & $\begin{array}{r}0.1 \\
13.3 \\
14.5\end{array}$ & $9.3 \pm 4.6$ \\
\hline
\end{tabular}

For data at $60 \mathrm{~mm}$ span, there are further concerns, because the effects of batch-to-batch variability have been exacerbated by low increases in energy. Table 2 shows two batches producing (small) negative increases in energy absorbed at $3.3 \% V_{\mathrm{f}}$ and one batch at $16.6 \% V_{\mathrm{f}}$ is effectively zero. Thus any potentially observable trend in Fig. 3 is masked by these effects.

In contrast, some conclusions may be drawn from data at the other span settings. At $40 \mathrm{~mm}$ span, the three data points in Fig. 3 show an approximately linear trend. Each of these data points are, however, means from three batches and, when a least squares fit of the nine individual batch values for energy increase (Table 2 ) is performed, the correlation coefficient $(0.540)$ indicates no linear correlation, statistically, at 0.05 significance level. 


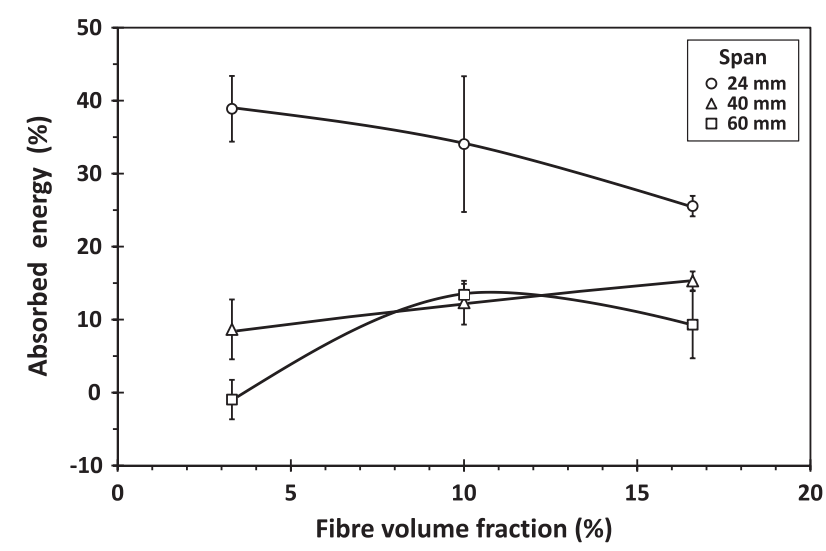

Fig. 3. Mean increases in impact energy (test samples relative to control counterparts) with standard errors, as a function of $V_{\mathrm{f}}$ (data from Table 2 ).

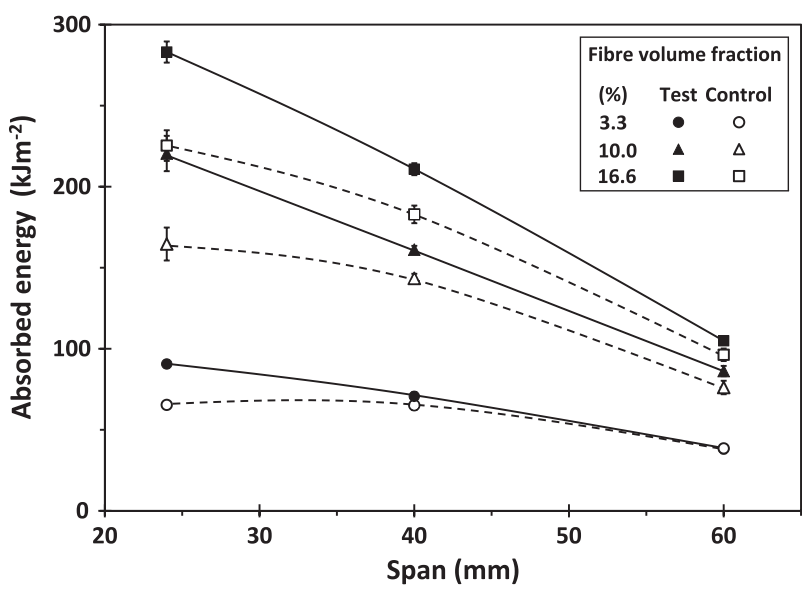

Fig. 4. Mean impact energies from test and control samples as a function of Charpy span setting. Data points with error bars (standard errors) are means from three batches (Table 2).

Although a linear relationship in the $40 \mathrm{~mm}$ span data may be ruled out, there is still a modest increase in energy absorbed by test samples, i.e. from $\sim 9 \%\left(3.3 \% V_{\mathrm{f}}\right)$ rising to $\sim 15 \%\left(16.6 \% V_{\mathrm{f}}\right)$. Because of error bar magnitudes however, a one-tailed $t$-test is required to compare the means at $3.3 \%$ and $16.6 \% V_{\mathrm{f}}$. This demonstrates that the observed increase at $16.6 \% V_{\mathrm{f}}$ is significant at 0.10 but not at the 0.05 level. Thus we may infer that there is only a weak positive trend between increase in impact energy and $V_{\mathrm{f}}$.

At $24 \mathrm{~mm}$ span, the increase in impact energy is reduced from $\sim 39 \%$ at $3.3 \% V_{\mathrm{f}}$ to $\sim 26 \%$ at $16.6 \% V_{\mathrm{f}}$, i.e. a $1 / 3$ reduction. A onetailed $t$-test ( 0.05 level) shows this reduction is statistically significant. Since this negative trend does not occur at the $40 \mathrm{~mm}$ span, we suggest it can be attributed to an increase in drag caused by the greater resistance from higher $V_{\mathrm{f}}$ samples being forced through the Charpy anvil supports following impact. Higher $V_{\mathrm{f}}$ samples will have been stiffer and thus more resistant to deformation (immediately after fracture) during this event, and resistance from drag provided by test or control samples (giving additional energy absorption) would have been similar, irrespective of prestress effects.

\subsection{Effects of span and fibre volume fraction on energy absorption}

By plotting the mean impact energy data for test and control batches as a function of span, Fig. 4 shows that with increasing

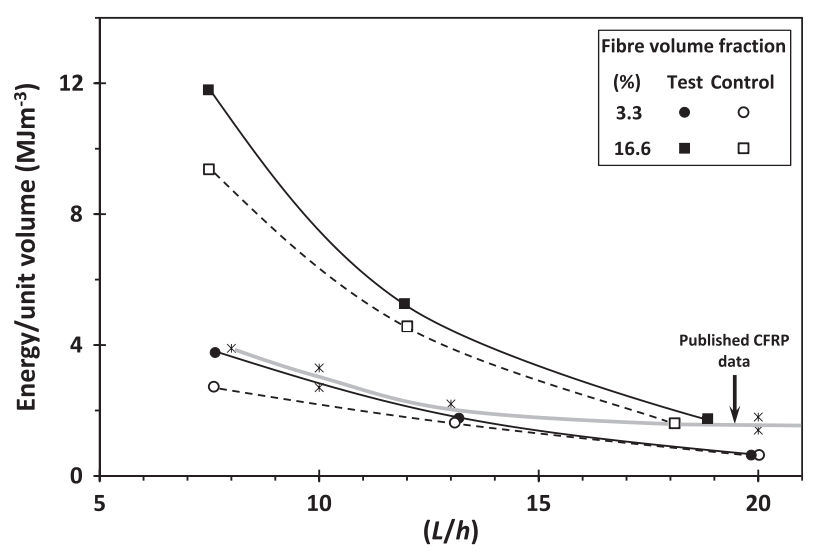

Fig. 5. Dependence of impact energy/unit volume, $u$, on $L / h$ ratio for test and control samples at $3.3 \%$ and $16.6 \% V_{\text {f. }}$. Also shown are CFRP data at comparable $h$ values from Ref. [15].

$L$ : (i) energy absorption by both test and control groups decreases and (ii) the increase in energy absorbed by test samples over their control counterparts diminishes. Additionally, (iii) the change in energy absorbed by control samples is less sensitive to a change in span for $24<L<40 \mathrm{~mm}$.

At larger spans, we suggest that (i) can be attributed to an increasing contribution from elastic deflection as the sample is forced through the anvil shoulders, with less contribution from fracture-inducing (plastic) deformation. Thus correspondingly less energy becomes absorbed from fracture-based mechanisms during the impact process. This concurs with the increasing prevalence of multiple vertical cracks and reduced residual deformation of samples at the larger span settings, reported in Section 4.1.

From (ii), we can deduce that increased energy absorption resulting from prestress must depend on the contribution from shear stress during impact, the latter decreasing as $L$ is increased. Since there is no prestress effect in the control samples, this may also explain (iii), in that their energy absorption characteristics would be less sensitive to increasing contributions from shear at the shorter span settings.

\subsection{Effects of span and fibre volume fraction on energy per unit volume}

Referring to Eq. (1), Fig. 5 shows plots of $u$ versus $L / h$ for test and control samples at the highest and lowest $V_{\mathrm{f}}$ values studied. The increasing contribution to energy absorption from shear stress-induced delamination is highlighted as $L / h$ is reduced. Also shown for comparison are data from Ref. [15] for unidirectional CFRP specimens over the same $L / h$ range $(L=30-100 \mathrm{~mm} ; h=3$ or $5 \mathrm{~mm}$ ). Although $V_{\mathrm{f}}$ for the CFRP is unknown, we expect it exceeded the $V_{\mathrm{f}}$ values used in our study.

As $L / h$ decreases, Fig. 5 clearly shows that $u$ for the $16.6 \% V_{\mathrm{f}}$ (unstressed) control samples increases faster than the CFRP data. This reflects the inherent toughness of the nylon fibre (even at relatively low $V_{\mathrm{f}}$ ), concurring with the energy absorbing capability of fibres being of great importance for low velocity impact resistance [25]. It is also apparent that at the lowest $V_{\mathrm{f}}(3.3 \%)$, brittle matrix characteristics become more prevalent. The (prestressed) test samples show higher $u$ values as $L / h$ decreases. This demonstrates the increasing effect of energy absorption from larger (shear stress-induced) delamination areas, referred to in Section 4.1.

As $L / h$ approaches 20 , both test and control samples at $16.6 \% V_{\mathrm{f}}$ show $u$ values comparable to the CFRP data. In contrast with the multiple vertical cracking observed in our samples at larger spans (Fig. 2) however, Ref. [15] reports the failure mode for their CFRP 


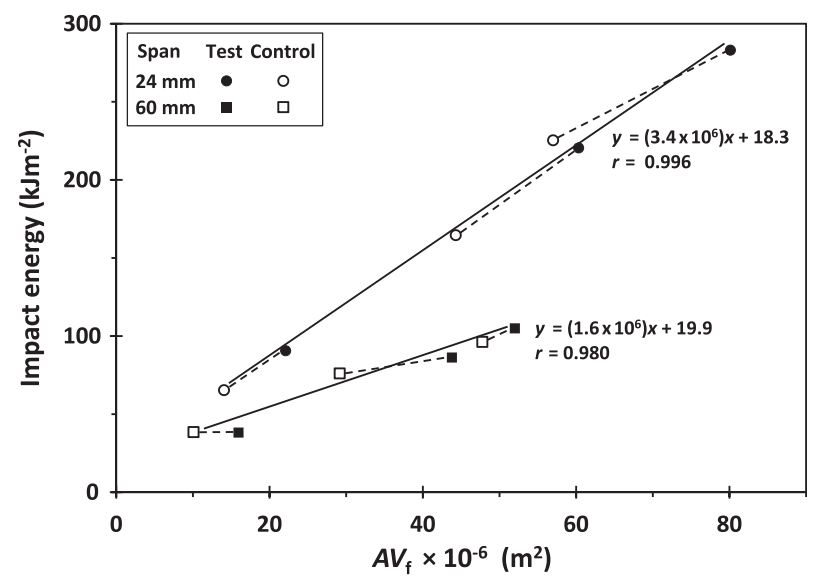

Fig. 6. Mean impact energies (from Fig. 4) at $24 \mathrm{~mm}$ and $60 \mathrm{~mm}$ span settings plotted against the product of estimated delamination area, $A$, and $V_{\mathrm{f}}$. Solid lines and equations are from linear regression; $r$ is the correlation coefficient.

samples $(h=3 \mathrm{~mm})$ to be complete separation break into two pieces and this clearly reflects their brittle nature. For values of $L / h>20$, we may infer from trends in Fig. 5 that if the nylon fibre composites reach a constant (minimum) value for $u$, it will be lower than the corresponding CFRP data and this can be attributed to the relatively low $V_{\mathrm{f}}$ values used for our composites.

\subsection{Effects of delamination area on energy}

To understand further the role of delamination on energy absorption, Fig. 6 plots impact energy data, from the maximum and minimum span settings, as a function of the product of estimated delamination area, $A$ (as seen in Fig. 2), and $V_{\mathrm{f}}$. The parameter $A V_{\mathrm{f}}$ provides a simple means to enable a more direct comparison of data for $A$ determined from samples with different $V_{\mathrm{f}}$ values. Since this approach assumes similar delamination profile characteristics through the thickness, $h$, of each sample, $A V_{\mathrm{f}}$ is not an accurate parameter. Nevertheless, Fig. 6 shows that the test and control sample data form approximately linear trends at both spans thus indicating some dependence of energy absorption on delamination area. These linear relationships can be compared with findings from impact tests on glass fibre-epoxy plate samples [26]. All test sample data points show higher $A V_{\mathrm{f}}$ values than corresponding control results, concurring with the larger delamination regions observed in Fig. 2. Of particular interest however, is the difference in gradients between the two span settings $\left(3.4 \times 10^{6} \mathrm{~kJ} \mathrm{~m}^{-4}\right.$ at $L=24 \mathrm{~mm}, 1.6 \times 10^{6} \mathrm{~kJ} \mathrm{~m}^{-4}$ at $\left.L=60 \mathrm{~mm}\right)$. The higher gradient value at $24 \mathrm{~mm}$ span indicates that energy absorption has a greater dependence on delamination than at $60 \mathrm{~mm}$. Data for $40 \mathrm{~mm}$ span (not shown for clarity) follow an intermediate gradient value $\left(2.5 \times 10^{6} \mathrm{~kJ} \mathrm{~m}^{-4}\right)$. The more prominent role of delamination at the $24 \mathrm{~mm}$ span clearly concurs with greater contributions from shear stress effects, as considered in Sections 4.3 and 4.4 .

\section{Discussion}

\subsection{Effects of span and fibre volume fraction on energy absorption}

Referring to Section 4.2, the selected span settings had a profound effect on how increases in energy absorption (from prestress) apparently changed with $V_{\mathrm{f}}$. For $L=24 \mathrm{~mm}$, the testing configuration was close to ISO 179 Specimen Type 3, the only difference being that the length of our samples $(80 \mathrm{~mm})$ was greater than that recommended by the standard (33 or $39 \mathrm{~mm}$ for (a)

TOP VIEW

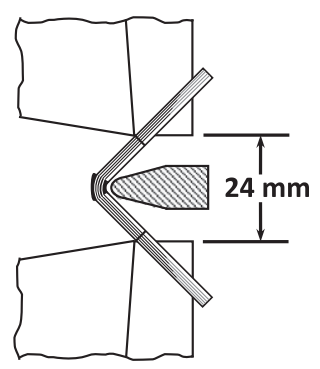

(b)
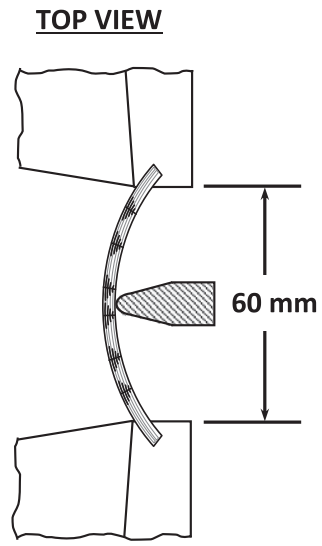

FRONT VIEW

FRONT VIEW

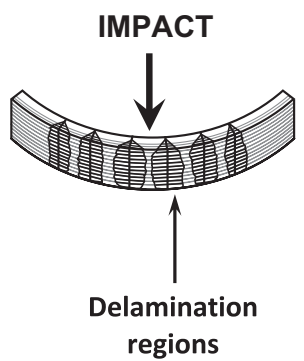

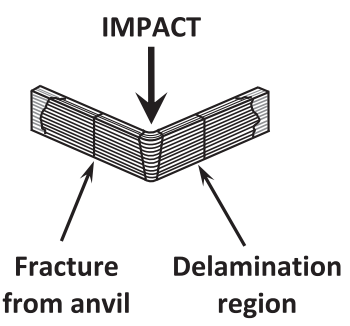

Fig. 7. Schematic of the fracture process at (a) $24 \mathrm{~mm}$ span and (b) $60 \mathrm{~mm}$ span.

$h=3 \mathrm{~mm}$ ). Although ISO 179 states that the most important (geometric) parameter is the $L / h$ ratio [13], our findings indicate that drag, especially from the higher $V_{\mathrm{f}}$ samples, has some influence on impact energy data at this $L$ setting. As illustrated in Fig. 7a, this must be expected: if the Charpy hammer pushes the fractured sample through the anvil shoulders following impact, clearance either side of the $10 \mathrm{~mm}$ wide hammer will only be $4 \mathrm{~mm}$ for a $3 \mathrm{~mm}$ thick sample. Although the longer sample lengths used in our study would have exacerbated the effect, it is highly probable that impact energy readings from shorter (Specimen Type 3) fibrereinforced samples, in which hinged (incomplete) breaks occur, would also be affected by drag. Fig. 7a also shows how the crack pattern seen in Fig. 2 is generated at $L=24 \mathrm{~mm}$.

For $L=60 \mathrm{~mm}$, the testing configuration was ISO 179 Specimen Type 2 . In contrast with shorter spans, the contribution to energy absorption from shear would have been comparatively small. Instead, following elastic deflection, our samples would have exhibited simple transverse fracture, had they been as brittle as CFRP (Section 4.4). Based on previous bend-test studies [7], we estimate that flexural modulus values for all our samples were $<10 \mathrm{GPa}$, i.e. very low in comparison with, for example, GFRP (55 GPa) or CFRP (120 GPa) specimens used for Charpy tests $[15,16]$. Thus although drag effects could have been negligible, samples deflecting elastically (prior to the onset of fracture mechanisms) will have been significant at the $60 \mathrm{~mm}$ span setting, as suggested in Section 4.3. Additionally, since the prestressed samples could have been up to $50 \%$ stiffer than their control counterparts [7], they may have absorbed more energy through elastic deflection, though we suggest that this addition to total energy absorption (as determined by final position of the Charpy hammer after impact) would have been comparatively small. Owing to limited support from the anvil base (only $10 \mathrm{~mm}$ overhang at each end of the sample) and degree of bending following elastic deflection, the onset of multiple vertical fractures (Fig. 2) would have enabled samples 
to be pushed through the anvil shoulders with relatively low energy absorption, resulting in little difference between test or control groups. Schematically, these effects are illustrated in Fig. 7b.

A further concern with the $60 \mathrm{~mm}$ span setting was the frequent tendency for samples to be struck off-centre by the Charpy hammer (Section 4.1). Vibrations and transient effects have been cited as complicating factors in pendulum-type impact tests [27] and dynamic analysis has demonstrated that a Charpy sample is not constrained as a simply supported three-point bend specimen [28]. Moreover, significant elastic deflection and limited support from the anvil base, coupled with uncertainty in the location of crack initiation (due to samples being unnotched), would have increased opportunities for unwanted lateral sample movement.

For $L=40 \mathrm{~mm}$, the effect of $V_{\mathrm{f}}$ can be assessed without complications associated with the other two spans being significant. Analysis of the data (Section 4.2) suggests only a statistically weak rise in energy absorbed by test samples (over their control counterparts) with $V_{\mathrm{f}}$. A previous study [6] has shown there is an optimum $V_{\mathrm{f}}(\sim 35-40 \%)$ at which VPPMCs provide the greatest improvement in tensile properties: this optimum was simply explained by the competing roles of fibres (which generate the available stress) and matrix (over which the stress can function). For Charpy (i.e. flexural) loading conditions, the situation is clearly much more complex. Three-point bend test studies [7] have indicated that the increase in flexural stiffness from viscoelastic prestress was insensitive to the limited $V_{\mathrm{f}}$ range studied (8-16\%) and, although samples were not fractured in Ref. [7], this insensitivity concurs at least, with the present findings.

\subsection{Influence of shear on impact performance}

The most significant finding from this work is that increased energy absorption arising from viscoelastically generated prestress depends principally on the presence of impact-induced shear stresses; these in turn activate residual (prestress-induced) shear stresses at the fibre-matrix interface to promote (energy-absorbing) delamination during the impact process. In Charpy impact tests, the contribution from impact-induced shear stress and therefore, prestress-enhanced delamination, increases as $L / h$ is reduced, thereby supporting the hypothesis in Section 2.2.

Attempting to make inferences on impact mechanisms occurring in large potentially complex composite structures, based on findings from the laboratory testing of samples with simple geometry, clearly requires caution. Beam-shaped samples, having lower levels of transverse constraint, are more capable of absorbing energy than larger structures, such as circular plates [25]. Moreover, with fibre reinforcement being unidirectional, our study was effectively performed on composite samples representing one-dimensional behaviour. Nevertheless, it is still possible to make some inferences on the likely effectiveness of VPPMCs in real-world structures.

Since enhanced energy absorption from the prestress effect depends principally on shear stress, low velocity impact protection from structures where deflection is restricted may be further improved with VPPMC technology. Clearly, deflection-restricted structures are not uncommon, and these include composite panels or plates with stiffeners for aerospace and underwater structures [29] and thick laminates, e.g. glass fibre composites for marine applications [30].

Predicting the effects of VPPMC principles applied to high velocity low mass impact conditions may be considerably more speculative than those of low velocity impact scenarios. Damage is however much more localised, so that geometrical aspects become less important [25]. Previous work has highlighted four mechanisms that may contribute to VPPMC energy absorption capabilities and, by considering circumstantial evidence from published studies, all of these could contribute towards improved high velocity impact protection [12]:

(I) Matrix compression impedes crack propagation.

(II) Matrix compression attenuates dynamic overstress effects, thereby reducing the probability of fibre fracture outside the area of immediate impact.

(III) Residual fibre tension causes the fibres to respond more collectively and thus more effectively to external loads.

(IV) Residual shear stresses at the fibre-matrix interface regions promote energy absorbing fibre debonding (delamination) over transverse fracture.

In the present study, impact-induced shear is shown to encourage Mechanism (IV) but in more general terms, this does not negate contributions from the other three mechanisms. The contribution from Mechanism (IV) may however be significant under high velocity low mass impact conditions, because the highly localised deformation will cause large shear stresses. This deformation generally consists of dishing or cone formation within the localised damage zone, as observed in composites reinforced with carbon [31,32], polymeric [33] and glass [34] fibres.

\section{Conclusions}

Charpy impact testing has been used to investigate the fracture and energy absorption characteristics of VPPMCs over a range of test span settings and $V_{\mathrm{f}}$ values. The main findings are as follows:

(i) The improvement in impact energy absorption from viscoelastically generated prestress depends principally on shear stresses activating prestress-enhanced fibre-matrix debonding (delamination) during the impact process. Thus a span setting of $24 \mathrm{~mm}$ shows greater increases in energy absorbed (25-40\%) compared with $60 \mathrm{~mm}(0-13 \%)$.

(ii) In contrast with relatively brittle composites such as CFRP, the mechanical properties (fracture characteristics, modulus) of the composite samples investigated here make the Charpy impact results much more sensitive to span setting. Thus although benefits from shear stresses are demonstrated at $24 \mathrm{~mm}$ span, higher $V_{\mathrm{f}}$ samples tested at this setting are increasingly affected by drag, as the fractured (hinged break) samples are forced through the anvil supports following impact. At larger span settings, particularly at $60 \mathrm{~mm}$, we suggest there is an increasing contribution to energy absorption from elastic deflection, at the expense of energy being absorbed from fracture-based mechanisms: this causes lower energy absorption from all samples (i.e. both test and control groups) as well as reducing any improvements from prestress effects.

(iii) Although higher $V_{\mathrm{f}}$ values may be expected to increase opportunities for energy absorption through prestressenhanced fibre debonding, results at (the intermediate) $40 \mathrm{~mm}$ span show there is no more than a small, positive, statistically weak trend between increased energy absorption (relative to control counterparts) and the $V_{\mathrm{f}}$ range studied (3.3-16.6\%).

Based on these findings, we suggest that for structures where deflection is restricted, low velocity impact protection may be further improved with VPPMC technology. Structures subjected to high velocity impact from low mass projectiles may also benefit, since large shear stresses would be expected to occur from highly localised deformation. 
In this work, we have highlighted some of the limitations of the Charpy impact test. Nevertheless, the improved understanding of energy-absorbing mechanisms from our findings could provide the basis for further, similar studies. By using fibre commingling techniques, investigating the effects of viscoelastic prestressing on the impact performance of relatively brittle composites (e.g. CFRP), would be of particular interest.

\section{Acknowledgements}

The authors would like to thank Garry Robinson for technical support. Departmental support (research degree fee waiver) for one of the authors (A.F.) is gratefully acknowledged.

\section{References}

[1] Hadi AS, Ashton JN. On the influence of pre-stress on the mechanical propertie of a unidirectional GRE composite. Compos Struct 1998;40(3-4):305-11.

[2] Motahhari S, Cameron J. Impact strength of fibre pre-stressed composites. J Reinf Plast Compos 1998;17(2):123-30.

[3] Motahhari S, Cameron J. Fibre prestressed composites: improvement of flexural properties through fibre prestressing. J Reinf Plast Compos 1999;18(3):279-88.

[4] Fancey KS. Fibre-reinforced polymeric composites with viscoelastically induced prestress. J Adv Mater 2005;37(2):21-9.

[5] Fancey KS. Investigation into the feasibility of viscoelastically generated prestress in polymeric matrix composites. Mater Sci Eng A 2000;279:36-41.

[6] Pang JWC, Fancey KS. Analysis of the tensile behaviour of viscoelastically prestressed polymeric matrix composites. Compos Sci Technol 2008;68:1903-10.

[7] Pang JWC, Fancey KS. The flexural stiffness characteristics of viscoelastically prestressed polymeric matrix composites. Composites Part A 2009;40:784-90.

[8] Fancey KS. Prestressed polymeric composites produced by viscoelastically strained nylon 6,6 fibre reinforcement. J Reinf Plast Compos 2000;29(15):1251-66.

[9] Fancey KS. A latch-based Weibull model for polymeric creep and recovery. J Polym Eng 2001;21:489-509.

[10] Fancey KS. A mechanical model for creep, recovery and stress relaxation in polymeric materials. J Mater Sci 2005;40:4827-31.

[11] Pang JWC, Fancey KS. An investigation into the long-term viscoelastic recovery of nylon 6,6 fibres through accelerated ageing. Mater Sci Eng A 2006;431:100-5.

[12] Fancey KS. Viscoelastically prestressed polymeric matrix composites potential for useful life and impact protection. Composites Part B 2010;41:454-61.

[13] BS EN ISO 179-1, Plastics - determination of Charpy impact properties, 2010

[14] Adams DF, Miller AK. The influence of transverse shear on the static flexure and Charpy impact response of hybrid composite materials. J Mater Sci 1976;11:1697-710.
[15] Nagai M, Miyairi H. The study on Charpy impact testing method of CFRP. Adv Compos Mater 1994;3:177-90.

[16] Tillie MN, Lam TM, Gerard JF. Insertion of an interphase synthesised from a functionalised silicone into glass-fibre/epoxy composites. Compos Sci Technol 1998;58:659-63.

[17] Hufenbach W, Ibraim FM, Langkamp A, Bohm R, Hornig A. Charpy impact tests on composite structures - an experimental and numerical investigation. Compos Sci Technol 2008;68:2391-400.

[18] Pegoretti A, Cristelli I, Migliaresi C. Experimental optimization of the impact energy absorption of epoxy-carbon laminates through controlled delamination. Compos Sci Technol 2008;68:2653-62.

[19] Khan MA, Ganster J, Fink HP. Hybrid composites of jute and man-made cellulose fibers with polypropylene by injection moulding. Composites Part A 2009;40:846-51.

[20] Ghasemnejad H, Furquan ASM, Mason PJ. Charpy impact damage behaviour of single and multi-delaminated hybrid composite beam structures. Mater Des 2010;31:3653-60.

[21] Golzar M, Poorzeinolabedin M. Prototype fabrication of a composite automobile body based on integrated structure. Int J Adv Manuf Technol 2010;49:1037-45.

[22] Guo J, Tang Y, Xu Z. Wood plastic composite produced by nonmetals from pulverized waste printed circuit boards. Environ Sci Technol 2010;44:463-8.

[23] Thomason JL, Ali JZ, Anderson J. The thermo-mechanical performance of glassfibre reinforced polyamide 66 during glycol-water hydrolysis conditioning. Composites Part A 2010;41:820-6.

[24] Amaro AM, Reis PNB, de Moura MFSF. Delamination effect on bending behaviour in carbon-epoxy composites. Strain 2011;47:203-8.

[25] Cantwell WJ, Morton J. The impact resistance of composite materials - a review. Composites 1991;22:347-62.

[26] Hong S, Liu D. On the relationship between impact energy and delamination area. Exper Mech 1989;29(2):115-20.

[27] Hogg PJ, Bibo GA. Impact and damage tolerance. In: Hodgkinson JM, editor. Mechanical testing of advanced fibre composites. Cambridge, UK: Woodhead Publishing Ltd.; 2000. p. 211-47.

[28] Marur PR. Charpy specimen - a simply supported beam or a constrained freefree beam? Eng Fract Mech 1998;61:369-86.

[29] Gong SW, Lam KY. Transient response of stiffened composite plates subjected to low velocity impact. Composites Part B 1999;30:473-84.

[30] Sutherland LS, Guedes Soares C. Impact characterisation of low fibre-volume glass reinforced polyester circular laminated plates. Int J Impact Eng 2005;31:1-23.

[31] Cantwell WJ, Morton J. Impact perforation of carbon fibre reinforced plastic. Compos Sci Technol 1990;38:119-41.

[32] Hazell PJ, Appleby-Thomas G. A study on the energy dissipation of several different CFRP-based targets completely penetrated by a high velocity projectile. Compos Struct 2009;91:103-9.

[33] Morye SS, Hine PJ, Duckett RA, Carr DJ, Ward IM. Modelling of the energy absorption by polymer composites upon ballistic impact. Compos Sci Technol 2000;60:2631-42.

[34] Sabet A, Fagih N, Beheshty MH. Effect of reinforcement type on high velocity impact response of GRP plates using a sharp tip projectile. Int J Impact Eng 2011;38:715-22. 